\section{A New Anti-malarial Drug}

THE valuable work of I. M. Tonkin and T. S. Work on two new anti-malarial drugs ${ }^{2}$ has brought to light the action of a well-known Eastern remedy. Dichroa febrifuga, of the family Saxifragacex, is a shrub found from China and north-eastern India to Java and the Philippine Islands. In the form of a decoction, the leaves and stems have been used in Indo-China for quotidian, tertian and quartan ague. When in India more than fifty years ago, a native physician sent to me some stems of the plant as a fever remedy and suggested that it might contain an alkaloid similar to quinine. The drug yielded no alkaloid but a glucoside, and differing from other astringent plants of this family it afforded no tannin. Later, a sample of the same drug was sent as a fever medicine used by the Chinese in Malaya. It is satisfactory to note that recent pharmacological research confirms the suitability of the specific namefebrifuga - given to the plant by Loureiro (Fl. Cochinale) so long ago as 1790.

5 Lower Church Road,

Weston-super-Mare.

${ }^{1}$ Nature, 156, 630 (1945).

\section{Tritanopia and Colour Vision}

THE existence of foveal tritanopia, in spite of the convineing observations of d'Alrutz (1909), Richardson-Robinson (1923) and Göthlin (1943), has been denied by those who, like Polack ${ }^{1}$, disagree with the trichromatic theory of colour vision and the classical division of dyschromatopsies. But the fact, already pointed out fifty years ago by König, has now been clearly evidenced by the results of Willmer and Wright ${ }^{2}$.

Does the cause of that dischromatism lie in the absence of cones specifically ruling the sensation of blue? In my opinion it rather lies in the replacement, in the 'blue' cones, of their specific photosensitive substance by the substance specific of the sensation of green : it is assumed that the common photosensitive substratum of those two receptors causes equal effects, expressed in the form of a 'bluegreen' sensation complementary to the 'red' sensation. This hypothesis accounts for the neutral spectral point, where is achieved that equality of action between the 'blue' and the 'green' cone on one hand and the 'red' cone on the other.

In deuteranopia, the photosensitive substance specific for the sensation of red must in the same way be found in the 'red' and the 'green' cones alike, which explains the sensation of yellow brought to light by the monocular anomalies.

It is, however, surprising that the visibility curve is but very slightly altered in deuteranopia as well as in tritanopia, for though the contribution of the blue component is almost negligible, that of the green component is essential.

In this respect, a long series of facts have led me to dissociate entirely light vision and colour vision ${ }^{3}$. I consider that the building up of the spectral response curves of the fundamental colours from chromatic equations, and the use of visibility coefficients very different from the coefficients of chromatic efficiency in order to fall back on the general curve of foveal visibility, are both based on an assumption which, in my opinion, is groundless. (For the same chromatic valence the quantities of light contributed by the 650,530 and $460 \mathrm{~m} \mu$ waves are, respectively (according to Wright), $0.648 ; 1.0 ; 0.05$.)

I admit that the receptor unit is made of a tetrad of cones and that three of those contain a photosensitive substance having, for each of them, different constants of absorption, with antagonistic interactions annulling the response when the three systems are equally stimulated; the fourth includes the three substances at the same time, but in unequal proportions (which accounts for the unequal efficiency of monochromatic waves), and brings on the sensation of light, that is, a sensation chromatically neutral.

If the 'green' cones include the substance for the sensation of red, and if in addition the neutral cone includes the 'green' substance, the visibility is not modified.

However, we can admit a slight contribution of the specific chromatic cones to the ganglion cell that gives the light message. When the 'green' or the 'blue' substances are missing in the corresponding cones, it is admitted that that chromatic modification accounts for the slight alteration of the visibility curve in deuteranopia and tritanopia.

In protanopes, the notable spectral shortening may be due to the lack of the 'red' substance, not only in the specific cone but also in the neutral cone which plays an essential part in the sensation of brightness.

Collège de France, Paris.

1 Polack, A., "Traité d'Ophtalmologie", 3, 339 (Paris, 1939).

Willmer, C. N., and Wright, W. D., Nature, 156, 119 (1945).

' Piéron. H. Sciences (Paris), 43, 267 (1943); Année Psychologique, 41-42, 125, and 148 .

\section{Bud Rot of Areca Palms in Mysore}

IN Hirethota, a village near Thirthahalli, Mysore State, a serious disease of areca palms has been rampant for the past fifty years. Locally the disease goes by the name 'hidimundige', which literally means the thinning out or tapering of the crown, gradually dwindling in diameter. But actually the disease in no way resembles the tapering stem wilt, better known as the 'pencil point disease' of coco-nuts so well known in the West Indies. A preliminary report of the investigations carried out is presented here.

On easual observation, no marked difference appears to exist between the healthy plants and the diseased ones. But an experienced observer can always spot the diseased plants in which the bud rot has set in, thereby preventing further growth of the plants. The leaves are gradually shed one after the other and finally the entire crown slips out, due to the rot at the base, leaving the bare stem. The time required for the infection to set in, to the stage of the final death of the trees, is spread over a period of several years. The yellowing or the wilting of the pinnæ, so characteristic of the red ring disease and the bronze leaf wilt of coco-nuts, does not appear to be a diagnostic character of the present disease.

The apices of several affected plants were cut and examined at various stages of infection. In the early stages, the discoloration of the still unfolded leaves in the stem apex is noticeable. This discoloration gradually extends downwards into the meristem, and finally the entire central spindle begins to rot, becoming converted into a soft, evil-smelling mass of tissue. The decay is enhanced by the secondary infections of bacteria and Fusarium sp. As pointed out by Nowell ${ }^{1}$ and Briton-Jones ${ }^{2}$, the findings of 